\title{
Introducción \\ Luces y sombras del patrimonio cultural como yacimiento de empleo
}

Lluís Bonet Agustí

Universitat de Barcelona. Grupo de Investigación en Economia, Gestión y Politicas Culturales

\section{Resumen}

Este artículo sirve de presentación a los contenidos del presente número de $\mathrm{PH}$ Boletín. El autor analiza el mercado de trabajo del sector patrimonial basándose en las categorias del economista Xavier Greffe (empleo directo, indirecto e inducido) al mismo tiempo que reflexiona sobre la evolución de los nuevos profesionales que se están perfilando en torno al sector, explicada más adelante por Rausell, Cabañés y Revert. Por otro lado, Lluís Bonet destaca los ámbitos que son actualmente motor de crecimiento económico y creación de empleo ligados al patrimonio: el turismo cultural tema central del artículo de Treserras y Matamalay las iniciativas llevadas a cabo en el medio rural aprovechando los recursos endógenos del territorio a partir del esfuerzo de gestión de las administraciones locales y gracias a los incentivos económicos de los programas europeos, análisis que recoge en su artículo Juan Alonso Sánchez.

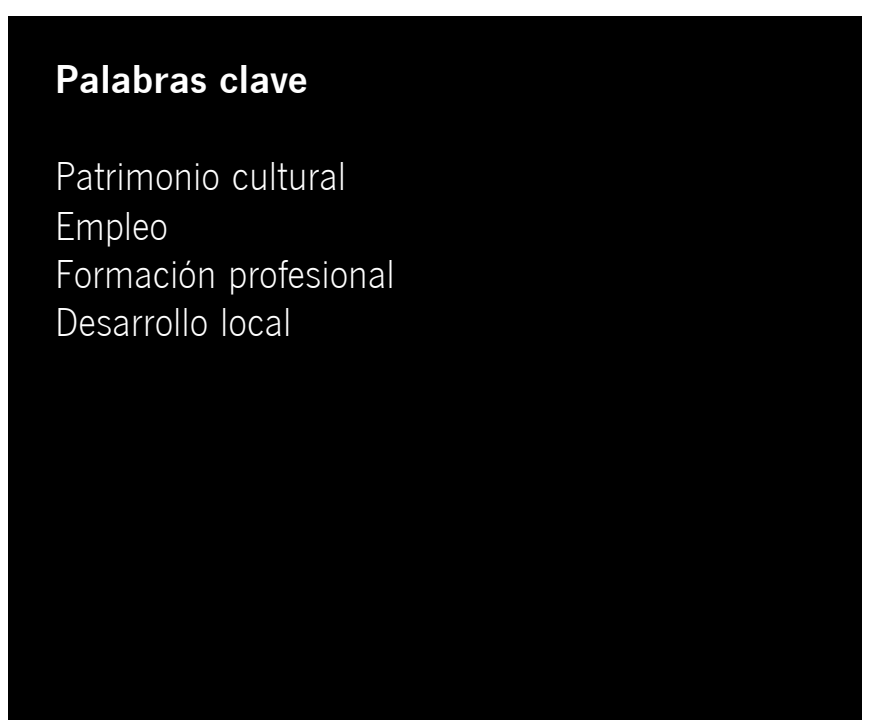

\section{¿Es el patrimonio un yacimiento de empleo?}

El Informe Delors o Libro Blanco sobre "Crecimiento, competitividad y empleo. Retos y pistas para entrar en el siglo XXI" de 1993 sorprendió a los profesionales del patrimonio, poco acostumbrados a pensar su trabajo en términos de valor económico, con una de las primeras referencias sobre la valorización del patrimonio cultural como yacimiento de empleo. Ahora bien, doce años después de la publicación de dicho informe es hora de preguntarse sobre las luces y sombras del mismo. Por desgracia, desde aquella fecha prácticamente no se han realizado en España estudios que permitan contrastar de forma rigurosa la realidad de dicha afirmación.

La puesta en marcha de numerosas instituciones y servicios patrimoniales ha generado sin duda un gran incremento del número de puestos de trabajo relacionados con el patrimonio, tanto en términos de empleo directo (en museos, archivos, empresas y servicios patrimoniales) como en empleo indirecto (por parte de los proveedores de dichas instituciones) o en empleo inducido (en comercios y servicios turísticos afines). Esta situación se ha dado como resultado del dinamismo inversor del sector público sobre la oferta, que ha generado a su tiempo un fuerte impulso positivo sobre la demanda doméstica y muy en especial la demanda turística. Las cifras globales de visitantes a museos y exposiciones ha crecido de forma continuada en las dos últimas décadas, y con ella la de los empleos relacionados con la actividad patrimonial.

Cabe señalar, asimismo, que buena parte de los servicios relacionados con ella son intensivos en factor trabajo. La propia acción de conservación y difusión del patrimonio está poco mecanizada con lo que todo incremento de la actividad se traduce en un aumento del número de trabajadores requeridos. Por otra parte, los servicios turísticos asociados (alojamiento, restauración o transporte) son también actividades intensivas en trabajo de difícil deslocalización, con lo que el impacto sobre la ocupación local es considerablemente alto. Analizado desde esta perspectiva parece evidente la capacidad del patrimonio como yacimiento de empleo.

De todas formas, sería necesario evaluar con más detalle el impacto real sobre la economía local de la inversión en patrimonio por tipologías de intervención. Por otra parte, faltan estudios sobre las características y nivel de calidad de los puestos de trabajo generados, así como sobre la productividad de los mismos. Este déficit de investigaciones aplicadas no nos permite más que una aproximación cualitativa al fenómeno. Justamente para reclamar una mayor atención hacia dicho aspecto y con el objetivo de ayudar a reflexionar sobre la situación del empleo patrimonial en España se proyectó este número de $\mathrm{PH}$ Boletín. En este contexto, el presente artículo sitúa las profesiones del patri- 
monio en un proceso de transformación, desde una lógica dominante de mercado público del empleo hacia otra más flexible, privada y precaria. Asimismo reflexiona sobre el impacto económico del patrimonio en el desarrollo local y el empleo, y analiza las políticas de fomento de la ocupación en dicho campo. Finalmente el artículo concluye con unas consideraciones y propuestas finales que permiten introducir los restantes artículos, proyectos e historias de vida que articulan la revista.

\section{Profesiones del patrimonio y mercado de trabajo}

Ampliación de servicios: ampliación del abanico profesional El número y características de las profesiones ligadas al patrimonio ha crecido substancialmente en los últimos veinte años a medida que se ampliaba la demanda social de servicios, y un mayor rigor y exigencia en el tratamiento de la protección y la difusión patrimonial. El abanico engloba desde el personal técnico de mantenimiento a los monitores del servicio educativo, de los arqueólogos para las intervenciones de urgencia a los programadores de rutas patrimoniales, de los transportistas de obras de arte a los documentalistas y comisarios de exposiciones temporales. Las necesidades de formación especializada, pero también de diálogo entre lógicas de intervención diversas, se disparan.

Como resultado de este proceso el campo profesional del patrimonio no lo ocupan hoy únicamente conservadores, arqueólogos o restauradores. Personal experto en comunicación, finanzas, educación o producción de eventos conforman hoy buena parte de la plantilla de licenciados universitarios de muchas instituciones patrimoniales. Hace un par de décadas, los conservadores asumían (a menudo sin una formación específica) buena parte de estas actividades. Algunos de estos nuevos profesionales son ajenos al campo, pero la mayoria proceden de licenciaturas en historia del arte o humanidades, y de una posterior formación en gestión. De todas formas, la relación entre una visión más centrada en la conservación y otra más abierta a las nuevas necesidades de la difusión e interacción social no siempre es fácil. En algunos casos, la confrontación entre prioridades esconde una lucha de poder y recursos entre profesionales con saberes distintos. Ambos perfiles deben aprender a dialogar entre sí, y a interpretar la demanda social de puesta en valor del patrimonio en un sentido amplio.

Pero el empleo ligado al patrimonio no se nutre únicamente de profesionales universitarios, sino de un sinfín de oficios técnicos y de personal subalterno para sus distintas funciones. La restauración de monumentos, obras de arte y sitios arqueológicos necesita de albañiles, estucadores, carpinteros o pintores, para citar sólo algunos oficios, con una formación y sensibilidad espe- cial hacia el patrimonio y las tecnologías tradicionales. El mantenimiento de museos y colecciones requiere asimismo de técnicos en sistemas en climatización, limpieza, informática, transporte, almacenaje o seguridad, con perfiles y niveles de responsabilidad muy dispares, de mozo de almacén o guarda de sala a comisario de policia experto en tráfico ilicito de obras de arte y antigüedades. La difusión y comercialización de productos patrimoniales plantea también un gran número de perfiles profesionales: vendedores de entradas, encargados de tienda, seleccionadores de producto, diseñadores de catálogos y páginas web, expertos en atracción de públicos, guías, intérpretes, educadores, etc. En el propio interior de los museos, el número de empleos creados como consecuencia del creciente número de librerías, tiendas, cafeterías y servicios diversos (del alquiler de audioguías a la gestión de las reservas de grupos) es enorme.

\section{El empleo público}

El trabajo en el ámbito del patrimonio ha dependido tradicionalmente de forma casi exclusiva del sector público. Museos, archivos, sitios arqueológicos o monumentos, así como los escasos servicios de investigación, restauración o conservación, se constituyen bajo titularidad y gestión pública. La necesidad de preservar un patrimonio históricamente muy expoliado aconsejó poner bajo la custodia gubernamental unos bienes que muy lentamente la sociedad hacía suyos para pasar a ser considerados de interés general.

Cabe decir que no siempre la titularidad pública ha sido garantía de conservación, así como tampoco la titularidad privada ha sido negativa, pues buena parte del patrimonio heredado ha llegado a nuestros días de la mano de coleccionistas privados. De todas formas es evidente que cuanto más estable es el titular de la custodia del patrimonio (la administración pública o la iglesia) más probabilidades hay de no expoliación o destrucción del mismo, aunque por desgracia -tal como demuestra la experiencia histórica- no siempre de correcta conservación. Sin embargo, la mejor forma de evitar la desidia, la falta de recursos o el abandono de responsabilidades por parte de sus titulares depende de la concienciación social general y de la capacidad organizada de presión de los propios profesionales del sector.

Hasta hace muy pocos años no se concebia otra forma segura de custodia gubernamental que no fuera la titularidad y gestión pública, pues se confundia titularidad con gestión. En la actualidad este binomio ha empezado a romperse en aras a una gestión más eficiente (aunque no sabemos si eficaz a largo plazo), pero subsiste en la mayor parte de equipamientos y servicios patrimoniales. Así pues, es lógico que el sector público sea aún hoy el principal empleador en el ámbito del patrimonio.

La descentralización política iniciada en España a inicios de la década de los ochenta, junto con el desarrollo de mayores res- 


\section{Introducción}

Luces y sombras del patrimonio cultural como

yacimiento de empleo
1. Albañil. Obras de restauración de la Puerta de Sevilla (Carmona)

2. Alfarero de Sorbas (Almería). Imagen: Isabel Dugo

\section{Lluís Bonet Agustí}

ponsabilidades culturales por parte de la administración local, permiten la puesta en marcha de un gran número de nuevas iniciativas y equipamientos patrimoniales. Por un lado, las comunidades autónomas crean sus servicios de patrimonio para coordinar e impulsar la acción gubernamental en dicho ámbito. Asimismo, ponen en marcha numerosas nuevas instituciones museísticas y arqueológicas. Por su lado, también los municipios medianos y grandes crean unidades administrativas de coordinación dotadas de personal técnico especializado. Finalmente, casi todas las administraciones locales de un cierto tamaño ponen orden a sus olvidadas colecciones, archivos y museos, dotándoles de personal profesional cualificado, y se lanzan a crear todo tipo de nuevos equipamientos.

El resultado de este proceso será la creación a lo largo de toda la geografía española de un número nunca visto antes de empleos públicos ligados al patrimonio. Buena parte de estas plazas se instrumentan bajo regímenes laborales bastante precarios, que sólo con el tiempo llegan a consolidarse dentro de los cánones administrativos convencionales. Dicha precariedad, característica de una administración voluntariosa pero con escasas atribuciones en dicho campo, y de un sector emergente poco reconocido socialmente, ha tenido como resultado la desazón de muchos profesionales que al lograr la plaza se acomodan y olvidan su ilusión inicial hacia la profesión. Un estudio aparte merecerian los becarios, a menudo el personal más voluntarioso de la institución pero pésimamente remunerado y no siempre bien tutorado.

\section{El empleo privado}

La creciente externalización de servicios por parte de la administración pública genera una nueva y amplia realidad de profesionales independientes y pequeñas empresas de servicios. Con la llegada de los años noventa se externalizan buena parte de los servicios colaterales (primero la seguridad y la limpieza, y de forma más selectiva, la restauración, la comercialización de productos o la vigilancia de salas, entre otros). Estos servicios habían sido prestados tradicionalmente por el personal de planta de museos o administraciones, y sólo en casos muy especializados, por profesionales independientes. Pero son los servicios técnicos más periféricos, temporales o de nueva generación (como por ejemplo los educativos, la edición de publicaciones o las excavaciones de urgencia) aquellos que ya de entrada se diseñan para ser proveídos externamente.

Dicho proceso conlleva la creación de un gran número de pequeñas empresas especializadas, y una transformación del trabajo del emple ado público. A éste último, cada vez más, ya no se le exige la ejecución de una exposición, la restauración de una obra o la puesta en marcha de programa educativo, sino ser capaz de diseñar y seguir la correcta provisión de dicho servicio por parte de profesionales externos. Así pues, actividades que hasta hace pocos años eran prestadas directamente por conservadores o funcionarios técnicos en patrimo- nio pasan a ser provistas por empresas de diseño y producción museográfica. Empresas con un núcleo central pequeño, pero con una mayor facilidad de subcontratación a profesionales especializados (normalmente una plantilla cercana al núcleo central).

El tránsito del profesional independiente a la consolidación de empresas está estrechamente ligado a la exigencia del procedimiento administrativo. Para poderse presentar a los concursos públicos es necesario disponer de cierta capacidad financiera, administrativa y técnica. Para ganarlos, se necesita además buenos contactos personales y políticos, o venir avalado por una gran experiencia anterior en lugares de referencia.

Otro instrumento que está favoreciendo la creación de empleo privado son los programas europeos de desarrollo regional (caso del LEADER y PRODER, entre otros) al poner en manos de entidades sin ánimo de lucro la gestión de sus proyectos, con estructuras de participación paritaria público-privada que integran los distintos intereses sociales y potencian la autogestión local (ver artículo de J.A. Sánchez). Muchos de los empleos creados bajo dichos programas son de naturaleza no directamente patrimonial (turismo rural, restauración, construcción y afines) pero inducidos por proyectos de rehabilitación y puesta en valor del patrimonio.

Muchas más oportunidades de empleo, mejor distribuidas territorialmente, pero menos estables

En términos generales, el mercado de trabajo en el sector del patrimonio es mucho mayor y flexible que hace unos años. Múltiples oportunidades aparecen dia a dia, gracias a la mejora de los equipamientos existentes o a la puesta en marcha de nuevos proyectos y espacios patrimoniales. Los profesionales más capacitados y conocidos son solicitados por diversos proyectos, hecho que permite algo insólito hace dos décadas en dicha profesión: la movilidad a lo largo de una carrera. Asimismo, para la creciente masa de jóvenes profesionales existen hoy muchos más lugares de trabajo, aunque se mantiene un enorme abismo entre el número de licenciados y graduados de postgrado y las plazas disponibles en el mercado de trabajo. El autoempleo o la creación de una empresa propia, apoyado en una actividad emergente o en un territorio con escasa competencia, suelen ser la alternativa.

Hasta hace muy poco tiempo, los escasos trabajos interesantes -y sin duda los más apetecidos- se concentraban en las grandes capitales, al amparo de las universidades o de los grandes museos. La descentralización política y la competencia entre territorios ha generado la puesta en marcha de un gran número de nuevos equipamientos con pretensiones a menudo interesantes, con lo que se han creado puestos de trabajo atractivos (en términos cualitativos pero también de remuneración y dignidad profesional) distribuidos por buena parte de la geografía del país.

Sin embargo, junto a este crecimiento de las posibilidades de tra- 
bajo, aumenta también la precariedad del empleo. Las escasas plazas existentes hace un par de décadas eran casi todas ellas de funcionario público. Conseguirlas era muy difícil, pero una vez ganado el puesto la estabilidad estaba garantizada. En la actualidad, el empleo público crece a un ritmo mucho más lento que el trabajo temporal o como profesional independiente. Los contratos por obra substituyen a menudo a la contratación indefinida, y ésta a su turno desplazó al personal funcionario. El mercado es mucho más amplio y a la vez más competitivo, pero los procedimientos de selección se caracterizan aún por un exceso de familiaridad y poco rigor.

Una de las características del actual sistema mixto de empleo es que genera bastantes agravios comparativos entre profesionales que comparten a veces no sólo el mismo espacio de trabajo sino también la misma o hasta una mayor responsabilidad. La incapacidad de los distintos gobiernos democráticos españoles para transformar el sistema laboral de la función pública se hace sentir de forma particularmente clara en un sector joven como éste. Comunidades autónomas y municipios han creado un sinnúmero de instrumentos jurídicos (consorcios, fundaciones públicas, institutos autónomos, etc.) para facilitar la gestión de los nuevos equipamientos o estructuras, y para encuadrar a sus profesionales en regímenes laborales más o menos precarios.

Otra tensión característica de la transición entre un modelo laboral de lógica gubernamental a otro más liberal se nota en la regulación de ciertas profesiones. Un caso paradigmático es el de guía turístico. Para defenderse del intrusismo y garantizar una mínima calidad de la visita se impone la obligatoriedad de unos estudios y un examen de habilitación. Dicha regulación permite profesionalizar unas actividades tradicionalmente muy estacionales y propensas a caer en manos de personal sin ninguna preparación y de empresarios con pocos escrúpulos. Pero al mismo tiempo no permite que un especialista en la materia pueda esporádicamente ejercer de guía ante unos colegas o estudiantes, o que un especialista extranjero desarrolle una visita que relacione bagajes y experiencias culturales distintas.

\section{Impacto económico del patrimonio sobre el desarrollo local y el empleo}

La multiplicación de iniciativas y la consolidación de equipamientos patrimoniales a lo largo de la geografía española durante las dos últimas décadas ha generado simultáneamente un fuerte incremento de la demanda, tanto doméstica como turística. La evolución del número de visitantes a museos y exposiciones, así como la demanda de servicios colaterales, ha crecido enormemente, con la consecuente creación de riqueza y empleos. La inversión pública en patrimonio se ha apoyado por un lado en el valor intrínseco del mismo, en térmi-
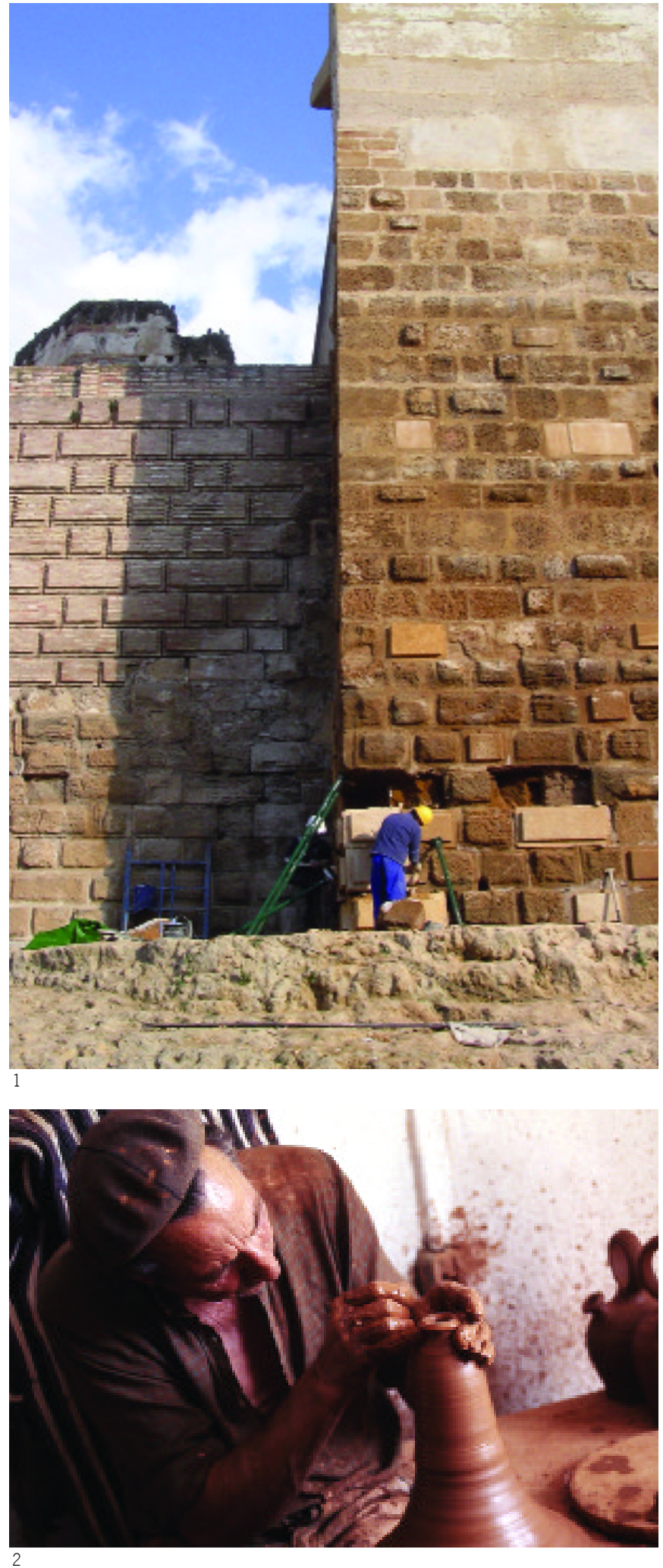


\section{Introducción}

Luces y sombras del patrimonio cultural como yacimiento de empleo

\section{Lluís Bonet Agustí}

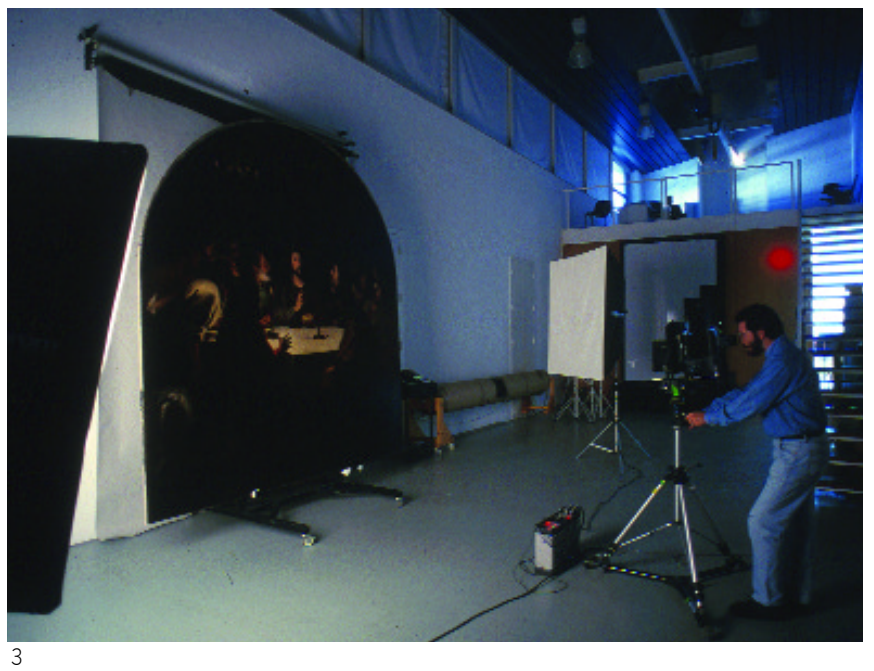

nos de valor de opción y legado, así como de prestigio, educación e identidad (Throsby 2001:110-123), y por el otro, en su impacto económico sobre el desarrollo local y el empleo.

Esta segunda dimensión ha sido utilizada para conseguir más recursos y legitimar mejor la inversión en patrimonio ante los responsables públicos y una sociedad cada vez más dominada por el paradigma económico. Más allá de su utilidad política, una de las ventajas de los estudios de impacto económico es que permite a una agencia gubernamental evaluar el impacto de su inversión en un proyecto o actividad en términos de coste de oportunidad en relación a otros proyectos alternativos. Se trata de comparar los gastos directos, indirectos e inducidos generados por todos los agentes relacionados con una actividad (desde la compra de entradas, el pago a los proveedores, o el gasto en restauración o aparcamiento del visitante), en relación al efecto generado por otras actividades.

Lógicamente, no sólo es importante sumar las rentas generadas (medida sobre la base del gasto realizado), sino también los costes o externalidades negativas del impacto (costes ecológicos, de congestión, de deterioro y restauración de una obra, o inflacionarios). El impacto económico total de una actividad cultural (por ejemplo, el Museo Guggenheim de Bilbao) sobre la economía local (Bilbao y su región metropolitana) debe medirse aislando el resto de variables coyunturales que inciden en la región en relación con la situación anterior a la inauguración del centro. En este caso paradigmático, sólo el incremento de la facturación turística inducida, y de los impuestos por ello recaudados, justifican la inversión realizada en su dia por el gobierno vasco, más allá de la rentabilidad artística, social o de recuperación de la imagen de la ciudad que pueda asociarse. Sin embargo, no siempre es posible aislar con tanta claridad el impacto de un evento cultural del conjunto de factores que inciden también sobre el
3. Fotógrafo. Imagen: Eugenio Fernández. Fototeca del IAPH

4. Personal de sala. Fundación Serralves (Oporto, Portugal).

crecimiento económico de una región.

Una segunda ventaja de estos estudios es que permiten analizar la inversión pública en patrimonio y su efecto multiplicador sobre el empleo. Las actividades patrimoniales, al ser intensivas en factor trabajo, tienden a ocupar un gran número de personas; este colectivo -en franco crecimiento en nuestro país- conforma el empleo directo del sector del patrimonio. Pero el impacto indirecto e inducido de la actividad patrimonial tiene asimismo grandes repercusiones en términos de empleo. Tanto los proveedores de servicio (seguridad, limpieza, actividades y servicios museográficos) como muchas actividades inducidas (servicios turísticos o de restauración) requieren de mucho personal local. Por esta razón, buena parte de los planes de desarrollo local recomiendan poner en valor e invertir en patrimonio como estrategia de generación de empleo.

La actividad con mayor impacto inducido en términos de renta y de ocupación es el turismo cultural. Cabe resaltar que, junto con los empleos creados en el sector turístico (alojamientos, restauración o transportes) o en sus actividades inducidas (construcción, equipamiento, servicios o industria alimentaria), destaca la industria de productos típicos de la localidad o de recuerdo. Buena parte de ellos son producidos en el entorno local más inmediato y tienen un gran impacto en términos de desarrollo local: artesanías y comida fundamentalmente (miel, quesos, embutido, vino, dulces, entre otros). La capacidad para crear productos originales que respondan a la demanda de los visitantes y poner en marcha pequeñas redes de distribución a escala local o subregional serán claves para que este efecto económico se quede en el lugar. Cabe decir, en este sentido, que la existencia de una red mundial de comercialización de recuerdos y artesanías con productos a muy bajo precio puede reducir la facturación de productos locales si no se es capaz de crear una imagen de marca y un marketing de lo genuino eficaz.

Otro ejemplo de estrategia positiva para el desarrollo local son las escuelas taller. La formación de jóvenes profesionales en oficios tradicionales, o con sensibilidad y conocimientos para intervenir en la restauración de monumentos y lugares patrimoniales, tiene una enorme repercusión económica y social sobre colectivos y lugares desfavorecidos.

\section{Dos grandes retos de la administración: resituar el perfil del gestor público del patrimonio e invertir en formación}

Nuevas responsabilidades del gestor público del patrimonio Tal como se ha comentado, hace escasamente dos décadas era casi impensable otra salida profesional en el ámbito del patrimonio que no fuera la función pública. Prácticamente todos los 
arqueólogos, historiadores del arte, restauradores o museólogos soñaban con ganar una plaza en los escasos museos o servicios públicos de patrimonio. Las posibilidades de encontrar trabajo (o de crearlo) en el sector privado eran casi inexistentes. El gran empleador de los licenciados en filosofía y letras (Io que hoy llamamos genéricamente humanidades) era el sistema educativo, y en muy pocas ocasiones se lograba trabajar en aquello en que uno se había especializado.

Los pocos que se colocaban en las instituciones patrimoniales del Estado ejercian funciones de ejecución directa sobre el patrimonio: programación, conservación o restauración. Hoy, con el incremento de las exigencias y funciones de las politicas patrimoniales, y la externalización de muchas tareas de intervención directa, se vive una transformación del perfil del gestor público en patrimonio, en especial del que trabaja en las estructuras de coordinación de ayuntamientos, diputaciones o comunidades autónomas. Al funcionario público se le exige menos ser un buen conservador o arqueólogo, mientras que se le requiere mucha más capacidad de diseño, organización e inspección del trabajo realizado por el personal propio o profesionales externos. La transición de uno a otro modelo no es fácil, pues se invierte poco en reciclaje profesional, y faltan instrumentos de apoyo a estas nuevas tareas (desarrollo de indicadores, análisis coste-beneficio social, o estudios sobre viabilidad a largo plazo del tejido de empresas y profesionales independientes, para citar sólo algunos ejemplos).

\section{La formación de la ciudadanía y los profesionales}

La acumulación de capital cultural por parte de la población depende de la escuela, las instituciones patrimoniales y los medios de comunicación, y el conjunto de sus profesionales, así como de la memoria histórica familiar o comunitaria, en este caso de responsabilidad colectiva. El papel del profesional -

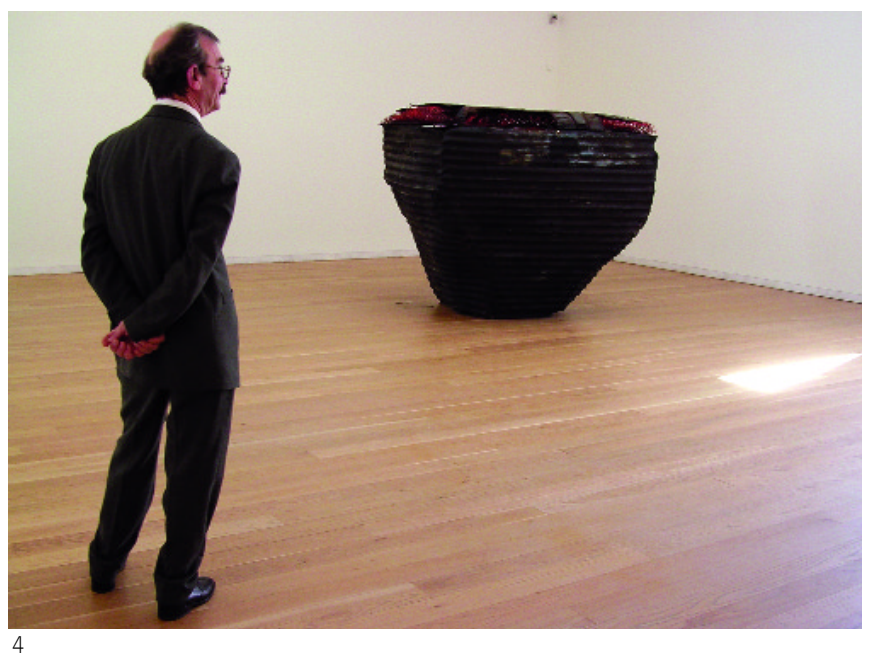

docente, comunicador, conservador o arqueólogo-, con sus intereses particulares y capacidad de transmisión, es en este contexto fundamental. En España, su formación ha sido una tarea principalmente gubernamental, aunque evidentemente es una responsabilidad compartida.

La ciudadanía asidua a los monumentos y museos -en estas latitudes una élite poco numerosa- se ha formado en la contemplación de las colecciones y exposiciones temporales (oferta sesgada hacia un legado histórico particular), y de forma muy parcial en los escasos programas pedagógicos existentes. Profesionales y administración son aquí responsables del lento tránsito de una museografía erudita, muy pobre en medios, a una museografía algo errática en términos de aciertos y fracasos, pero en estos últimos años con muchísimos más medios económicos y técnicos. Por desgracia, la cenicienta de esta positiva evolución del panorama museológico la conforman los servicios pedagógicos, que al ser poco valorados por el establishment museístico cuentan en general con pocos medios.

Junto a los profesionales del patrimonio, el sistema educativo (planes de estudio, metodología docente y capacidad de transmisión del profesorado) tiene también una gran responsabilidad en la formación de los futuros visitantes. Históricamente ha educado (o malformado) a los ciudadanos con aproximaciones poco científicas o sesgadas como consecuencia de una utilización politica de la historia, en especial bajo las dictaduras. Periodistas y medios de comunicación juegan también un papel creciente en el proceso de valoración social del patrimonio. Noticias y documentales, pero también la imagen proyectada por algunas películas o la publicidad tienen una gran influencia en la percepción de la propia historia, las profesiones patrimoniales (Indiana Jones como emblema) y la cultura del resto del mundo.

En un mundo en rápida transformación, la acumulación de experiencias, conocimientos y la especialización progresiva depende en buena manera de la estabilidad y exigencias del mercado laboral, pero también del proceso de integración al mismo. La formación continua es una necesidad crucial escasamente valorada por empresas e instituciones, y en el actual contexto cada vez más en manos de los propios profesionales debido al creciente número de trabajadores autónomos. Para un profesional, formarse no implica solamente incorporar nuevo capital cultural en su acervo, sino también aquel capital social que permite sinergias y el desarrollo de trabajo en red.

Por lo que concierne a la formación de base, las nuevas demandas de especialización no siempre están directamente relacionadas con la de los estudios existentes, o de aquello que demandan los propios estudiantes. Al recién licenciado en historia del arte le cuesta asimilar que el mercado de trabajo no está en la crítica de arte o en la investigación, sino en la transformación de 


\section{Introducción}

Luces y sombras del patrimonio cultural como yacimiento de empleo

\section{Lluís Bonet Agustí}

un recurso patrimonial en un producto turístico cultural viable. Las deficiencias en señalización, en comercialización, o en el diseño de rutas, itinerarios o productos atractivos tienen siempre detrás profesionales poco sensibles a las nuevas demandas y con una formación para ellas insuficiente. Evidentemente, parte de dicha responsabilidad está en los docentes y en los programas universitarios, más al servicio de sus intereses gregarios que en los de la sociedad a la que sirven.

Finalmente, es necesario analizar las políticas generales de fomento del empleo y su impacto en el sector del patrimonio. España puede presumir de un programa estrella en este campo, las escuelas taller y casas de oficio en patrimonio. Financiado gracias al Fondo Social Europeo, pero con recursos adicionales de comunidades autónomas y ayuntamientos, ha permitido restaurar sitios en España y Latinoamérica (ver artículos de Sánchez Martínez y Gómez Pallete). Sin embargo, aparte de este programa, el INEM no ha desarrollado otras políticas activas ni dispone de datos desagregados sobre empleo o paro del sector, entre otras cosas porque los epígrafes utilizados no corresponden al ámbito del patrimonio.

\section{A modo de conclusión}

Luces y sombras en los mercados de trabajo patrimonial La primera conclusión a que uno llega cuando se aproxima al estudio del empleo en el ámbito patrimonial es su heterogeneidad, asi como la escasez de datos y de análisis rigurosos sobre el mismo. Las grandes cifras del sector muestran el gran crecimiento del número de museos e instituciones patrimoniales, y de sus visitantes, pero no nos hablan de su gestión y situación interna. Sabemos que el empleo también ha crecido y diversificado, pero faltan estudios que nos hablen con detalle de la calidad de este trabajo, su estabilidad laboral, o el coste social (la inversión en años de formación y reciclaje) comparado con la remuneración obtenida, para citar sólo algunos ejemplos.

Por otro lado, los escasísimos estudios de impacto económico sobre el empleo indirecto o inducido se han realizado desde proyectos exitosos (Guggenheim, Alhambra...) y no permiten extrapolar sus resultados hacia el conjunto del sector. Es este sentido, la capacidad multiplicadora real de la inversión en patrimonio sobre la creación de empleo indirecto e inducido (el llamado factor arrastre), en comparación con otras actividades de servicios menos dependientes de la inversión pública, necesitaría ser evaluada con rigor.

Ligada a esta cuestión, convendría valorar la productividad de dichas actividades, en especial cuando la calidad del acceso a la experiencia patrimonial depende cada vez más, en un mundo crecientemente globalizado, del uso intensivo de las tecnologías de la

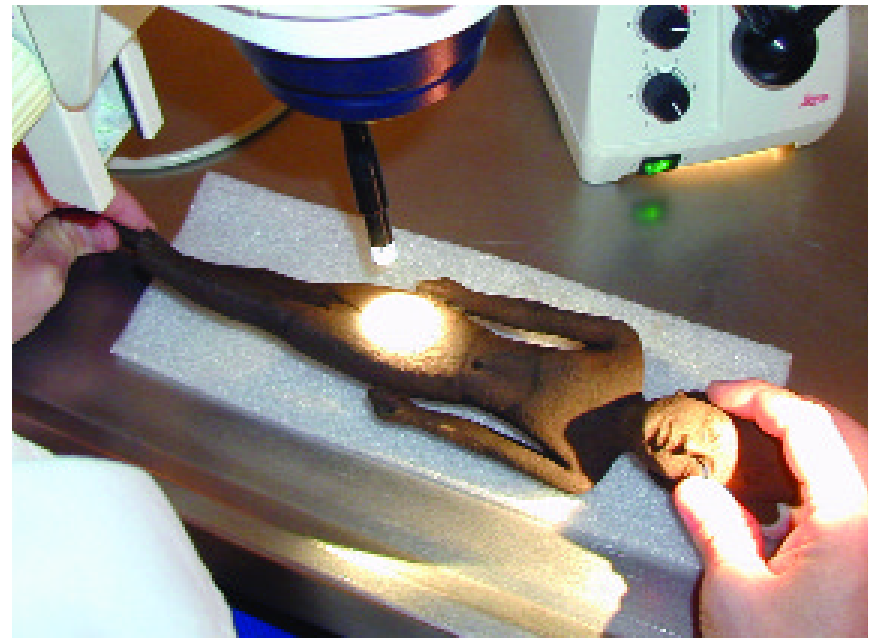

información y la comunicación. La competitividad de un país, y de sus propuestas patrimoniales, es fruto de la combinación de la consecución de un cierto reconocimiento histórico, junto con la capacidad por ofrecer un producto de calidad y saber potenciar una imagen de marca cada vez más apetecible. La productividad está pues en la calidad y formación del recurso humano.

En España se ha empezado a trabajar en esta dirección, aunque el camino por recorrer es aún largo, y requiere una gran capacidad de adaptación local. En este sentido, es fundamental tener en cuenta las potencialidades y límites de absorción temporal o espacial del propio patrimonio y sus respectivas comunidades. Eso vale tanto por los equipamiento al borde del colapso (Altamira o la Alhambra han resuelto correctamente el dilema) como por aquel patrimonio que no logra situarse en el mapa mental de sus ciudadanos o de los flujos turísticos. Ahora bien, la gestión colectiva de un patrimonio es siempre más compleja que la de un sitio individual. Un caso emblemático de gestión compleja es el de la ciudad de Barcelona, pues gracias a su éxito, ha pasado de 1,7 a 4,5 millones de turistas y de 3,8 a 10,1 millones de pernoctaciones entre 1990 y el 2004, gracias a su oferta cultural y patrimonial, y a la excelente labor de promoción desarrollada (Bonet 2001), puede en pocos años perecer de éxito si no garantiza una experiencia de calidad ante la masificación creciente de sus espacios más emblemáticos.

Desde una perspectiva más centrada en las condiciones de trabajo, el sector debe enfrentarse sin hipocresías al problema de las asimetrias entre niveles de responsabilidad, compromiso y remuneración del trabajador. El papel de los becarios debe regularse en beneficio de todos, sobre todo en términos de aprendizaje (la institución patrimonial no sólo puede beneficiarse del trabajo del becario, sino que debe invertir en su formación). Otra cuestión, poco desarrollada en España, es la del 
5. Técnico de laboratorio de metales. Imagen: Fondo gráfico del Centro de Arqueología Subacuática (IAPH)

6. Restaurador de escultura. Imagen: Eugenio Fernández. Fototeca del IAPH

7. Artesana textil. Almonaster la Real (Huelva). Imagen: Victor Fernández Salinas

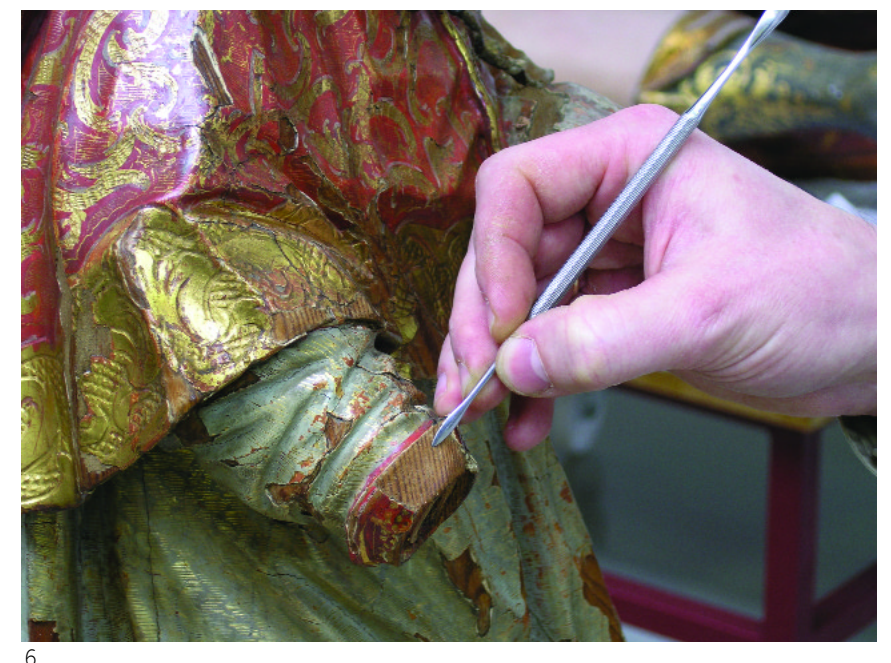

voluntariado. Tiene una cierta importancia en el ámbito rural o en proyectos emergentes o de denuncia, pero el modelo dominante en las escasas asociaciones de amigos de museos, sitios y monumentos tiene poco que ver con el modelo anglosajón. Dados los valores sociales y la cultura organizativa de este pais, favorecer un mayor compromiso de la sociedad civil respecto al patrimonio no pasa tanto por el trabajo voluntario sino por su doble implicación como usuarios asiduos y ciudadanos exigentes.

En veinte años el empleo creado por la actividad patrimonial en España ha sido mucho, pues el sector ha merecido por primera vez en la historia contemporánea del país cierta atención por parte de las autoridades públicas. Su capacidad para alimentar otras actividades a su alrededor ha sido asimismo importante, aunque no dispongamos de cifras rigurosas que permitan cuantificarlo. Ambas realidades han ayudado a legitimar la inversión en dicho campo, aunque quede camino por recorrer en términos de calidad e impacto social. Mi objetivo, con las precedentes reflexiones, no era otro que introducir un boletín que va mucho más allá de las impresiones personales de un académico. Así, pues, vamos a presentar sintéticamente sus ambiciones y contenidos.

\section{Bibliografía}

ALONSO, J.A.; SANZ, M. (2000) El Patrimonio histórico de España desde una perspectiva económica: una primera aproximación al gasto en conservación, restauración y rehabilitación del patrimonio histórico español. Madrid: Fundación Caja Madrid, 2000

BIANCHINI, F. (2002) "Cultura e sviluppo del territorio: un quadro delle professioni emergenti". Economia della Cultura, n² 1, 2001, pp. 7-19

BONET, L. (2004) "La estrategia cultural de Turisme de Barcelona, un consor-

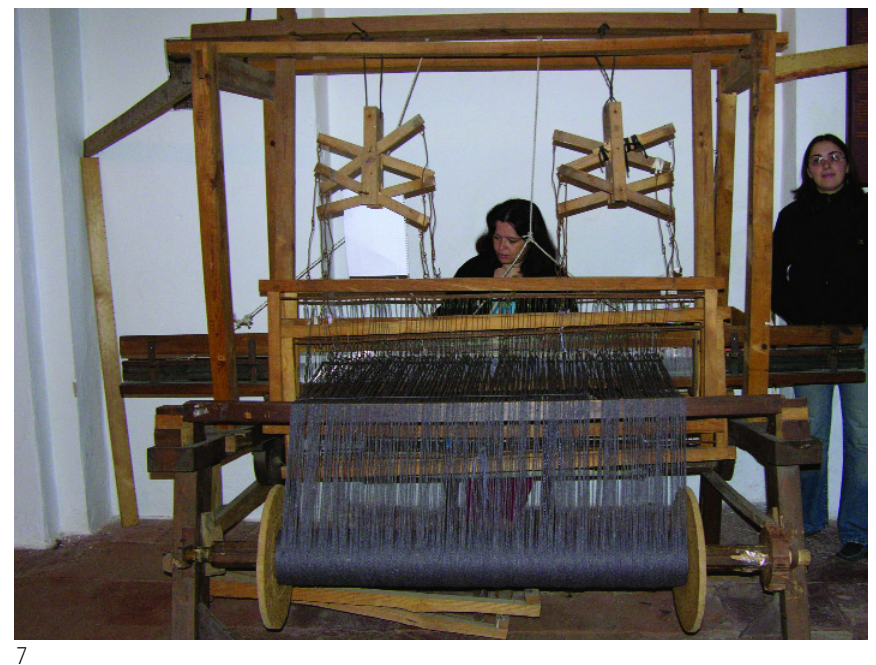

cio público-privado de éxito", en FONT, J. (Coord.) Casos de turismo cultural. De la planificación estratégica a la gestión del producto. Barcelona: Ariel, 2004, pp. 235-259

BONET, L. (1996) "Nuevas posibilidades de empleo relacionadas con las innovaciones en la gestión y administración del museo. Nemus. Informe Español". PH: Boletín del IAPH, n 17, 1996, pp. 78-85

CABASINO, E. (2002) "I mestieri dei beni culturali: dalle torri d'avorio alla prova del mercato". Economia della Cultura, n 1, 2001, pp. 41-49

GREFFE, X. (2003) La valorisation économique du patrimoine. París: La documentation Française, 2003

KOTLER, N; KOTLER, P. (2001) Estrategias y marketing de museos. Barcelona: Ariel, 2001

TRHOSBY, D. (2001) Economía y cultura. Madrid: Cambridge University Press, 2001

VALENTINO, P.A; MosSeTto, G. (2001) Museo contro museo. Le strategie, gli strumenti, i risultati. Firenze: Giunti, 2001 